\title{
Enhanced alginate capsule properties as a formulation of entomopathogenic nematodes
}

\author{
Jinwon Kim • Geoffrey Jaffuel • \\ Ted C. J. Turlings
}

Received: 12 May 2014 / Accepted: 12 November 2014/Published online: 29 November 2014

(C) International Organization for Biological Control (IOBC) 2014

\begin{abstract}
Despite many advantages of employing entomopathogenic nematodes (EPNs) as biocontrol agents against soil-dwelling insect pests, their use is still limited to home gardening or small-scale farming. Lack of cost-effective, durable formulations, as well as appropriate application methods have so far prevented the use of EPN in large-scale farming. A recent report on alginate capsules as a novel EPN formulation for application into the soil shows promise. However, EPNs often readily escaped from these capsules within a few days especially when they are not refrigerated. To improve EPN retainment, we adjusted capsule properties by changing the reaction temperature for capsule formation and by adopting post-treatment of alginate capsules with excessive $\mathrm{Ca}^{2+}$, and then evaluated EPN escape from the
\end{abstract}

Handling Editor: Ralf Ehlers.

Electronic supplementary material The online version of this article (doi:10.1007/s10526-014-9638-z) contains supplementary material, which is available to authorized users.

J. Kim · G. Jaffuel · T. C. J. Turlings ( ()

Institute of Biology, University of Neuchâtel,

Rue Emile-Argand 11, 2000 Neuchâtel, Switzerland

e-mail: Ted.Turlings@unine.ch

Present Address:

J. Kim

Applied Zoology/Animal Ecology, Dahlem Centre of

Plant Sciences, Freie Universität Berlin,

Haderslebenerstr. 9, 12163 Berlin, Germany capsules manufactured under different conditions. While capsules with the hardest capsule shell were produced at $4{ }^{\circ} \mathrm{C}$ with the $\mathrm{Ca}^{2+}$ post-treatment, the $40 \%$ enhanced EPN retainment was achieved only by lowering the reaction temperature.

Keywords Entomopathogenic nematodes - Alginate capsules · Formulation for entomopathogenic nematodes $\cdot$ Capsule properties

\section{Introduction}

Entomopathogenic nematodes (EPNs) show tremendous potential as biocontrol agents, especially for the control of soil insect pests, with rapid killing-power and an environment-friendly mode of action (Lewis et al. 2006). When infectious juveniles (IJs), the free-living and host-finding stage of EPNs, find and enter a host they will kill it within two days and multiply into tens of thousands of new IJs from one host insect, each of which will search for a new victim (Kaya and Gaugler 1993). Furthermore, EPNs do not cause environmental problems such as soil and water contamination and have limited undesirable effects on non-target organisms under natural conditions (Peters 1996).

Despite their obvious potential, commercial successes of EPN application are rare (Georgis et al. 2006) and their usage is still limited to home gardening and small-scale farming for a few but critical 
reasons-(1) IJs do not eat until they find a new host (Shapiro-Ilan et al. 2006; Koppenhöfer 2007) and thus the activity and the infectiousness of EPNs can rapidly decrease over time. This limits the shelf life of EPN products and, even after refrigerated storage, EPNs are best applied within 2-3 days after purchase (ShapiroIlan et al. 2006). (2) Current methods of EPN application, i.e. spraying water suspension of EPNs onto plants or soil, are comparatively labor and cost intensive and less efficient (Shapiro-Ilan et al. 2006). A limited number of EPNs will reach the rhizosphere of plants where they can properly act on the target insect pests. (3) IJs are very susceptible to desiccation and UV radiation (Gaugler et al. 1997). It is therefore recommended to apply EPNs early in the morning or late in the afternoon. (4) IJs readily settle in water. Hence, it is desirable to agitate the EPN solution from time to time for uniform distribution of EPNs over the field. For these reasons, many research efforts focus on the development and improvement of EPN formulations and application methods (Georgis and Kaya 1998; Shapiro-Ilan et al. 2006).

An increasing number of studies explore the use of capsules made of biocompatible and biodegradable natural polymers as a formulation of microorganismal biocontrol agents including EPNs (John et al. 2011; Vemmer and Patel 2013). Entomopathogenic nematodes are expected to be more protected in polymerbased capsules from abiotic hardships such as desiccation and UV radiation and from biotic stressors such as their natural enemies. In addition, the efficacy of EPNs may be enhanced by co-encapsulation of biological or chemical pesticides that are compatible with EPNs (Shapiro-Ilan et al. 2004, 2012) or other ingredients that may divert insect feeding from the roots of crop plants towards EPN capsules (Hiltpold et al. 2012).

Alginate is currently the most promising biopolymer for encapsulation of viable cells or microorganisms for medical purposes (King 1982; Hoffman 2012). Alginate, abundant in and isolated from brown algae, is composed of $\beta$-D-mannuronate and $\alpha$-Dguluronate with varying ratios depending on the algal source (King 1982). Alginate polymer molecules dissolved in water are negatively charged under neutral to alkaline $\mathrm{pH}$ conditions and form a hydrogel in the presence of metal cations such as calcium via inter-polymer ionic crosslinking. Being biocompatible and biodegradable, alginate capsules have the potential for a wide range of medical and agricultural applications, as carriers of medical and agricultural ingredients for drug delivery or insect pest control, respectively (Tønnesen and Karlsen 2002; John et al. 2011; Vemmer and Patel 2013).

Several reports document encapsulation of EPNs in $\mathrm{Ca}^{2+}$-alginate capsules (Kaya and Nelsen 1985; Kaya et al. 1987; Hiltpold et al. 2012). Kaya and Nelsen (1985) were the first to produce EPN-containing capsules by adding the EPN-containing alginate solution dropwise into the $\mathrm{CaCl}_{2}$ solution, resulting in the capsules of about $1.5 \mathrm{~mm}$ in diameter with a solid core in which EPNs were immobilized. Insects were orally infected by feeding on the EPN capsules (Kaya and Nelsen 1985). An elegant addition to this approach is the co-encapsulation of EPNs with tomato seeds: as the tomato seeds germinate, the capsules are opened, liberating EPNs that can then infect and kill insect hosts (Kaya et al. 1987). More recently, Hiltpold et al. (2012) developed a method to produce capsules of 4-5 $\mathrm{mm}$ in diameter with EPNs encapsulated in the liquid core by dripping the solution of non-toxic Gluco $^{\circledR}$ (a mixture of calcium salts of lactic and gluconic acids) containing EPNs into the alginate solution. Xanthan, a sugar polymer compound, was added to increase viscosity of the capsule forming solution, which made production of sizable EPN capsules possible. In field tests such EPN capsules were buried in the rhizosphere of maize and the EPNs released from the capsules were shown to be effective in controlling the coleopteran root herbivore, the Western corn rootworm (Diabrotica virgifera virgifera). However, EPNs were found to escape readily out of the capsules within a few days after encapsulation especially when stored at room temperature, which is undesirable for commercialization.

In this study, we explored the possibility to produce EPN capsules described by Hiltpold et al. (2012) with enhanced retainment of EPNs. From preliminary experiments, we hypothesized that alginate capsules with enhanced EPN retainment may be produced by building capsule shell with a more finely intertwined $\mathrm{Ca}^{2+}$ alginate framework and that the structural fineness will result in increased resistance to mechanical rupturing. We adopted two strategies to strengthen the alginate capsule shell: (1) production of alginate capsules at lower reaction temperature and (2) post-treatment of alginate capsules with excessive $\mathrm{Ca}^{2+}$ ions. At lower reaction temperature, the movement of alginate molecules should be slower and non-uniformly linear 
alginate molecules, otherwise stacked loosely, will be given more time to pile up closely and evenly on the capsule shell. In addition, post-application of excessive $\mathrm{Ca}^{2+}$ ions was expected to result in more ionic links within and among alginate polymers, forming dense $\mathrm{Ca}^{2+}$-alginate network. To test these hypotheses, we compared shell thickness and capsule hardness of alginate capsules produced at different reaction temperatures with or without $\mathrm{Ca}^{2+}$ post-treatment. Then, the retainment of EPNs in alginate capsules was evaluated by determining EPN escape from alginate capsules manufactured under different conditions.

\section{Materials and methods}

EPNs, insects and encapsulation materials

Infectious juveniles of Heterorhabditis bacteriophora Poinar (Heterorhabditidae: Rhabditida) were kindly provided by Andermatt Biocontrol AG (Grossdietwil, Switzerland) and the colony was maintained in the laboratory with the final instar larvae of the waxmoth (Galleria mellonella L.) as previously described (Kaya and Stock 1997). The waxmoth larvae were purchased at a local fishing shop. EPNs that emerged from $G$. mellonella cadavers were stored for a maximum of seven days at $12{ }^{\circ} \mathrm{C}$ until encapsulation. Sodium alginate, Gluco ${ }^{\circledR}$ (a mixture of calcium salts of lactic and gluconic acids) and xanthan were purchased from Solé Graells (Barcelona, Spain), $\mathrm{CaCl}_{2} \cdot 2 \mathrm{H}_{2} \mathrm{O}$ from Fluka (Buchs, Switzerland) and the blue food dye from Schneitter (Neuchâtel, Switzerland). We used deionized water throughout this research.

\section{Capsule formation under different conditions}

Alginate capsules were manufactured at room temperature (ca. $24{ }^{\circ} \mathrm{C}$ ) or on ice (ca. $4{ }^{\circ} \mathrm{C}$ ) and with or without $\mathrm{Ca}^{2+}$ post-treatment as follows. Alginate solution $\left(0.5 \%\right.$, w/v) and $\mathrm{Ca}^{2+}$-xanthan solution [capsule core solution; $2 \%$ Gluco $^{\circledR}$ (w/v), $0.4 \%$ xanthan (w/v), $0.05 \%$ blue dye (v/v)] were prepared, degassed in vacuo and stored at $12{ }^{\circ} \mathrm{C}$ for a maximum of five days. Without degassing, bubbles would form in the capsule shell, which prevents even growth of the shell. A droplet of $\mathrm{Ca}^{2+}$-xanthan solution was dripped from a 1-ml disposable syringe into $20 \mathrm{ml}$ of alginate solution in a $50-\mathrm{ml}$ glass beaker preconditioned at room temperature or on ice. Formation of capsule shell was visible within seconds. Every $2-3 \mathrm{~min}$, the alginate solution was gently agitated for about 10-20 s with a spatula without touching the growing capsule. This prevented the capsule from settling on the bottom of the beaker and allowed the capsule shell to grow uniformly around the core. After $20 \mathrm{~min}$ of capsule formation, the capsule was removed from the reaction beaker with a spatula and rinsed for $30 \mathrm{~s}$ with excessive water in another beaker while gently stirring. For the $\mathrm{Ca}^{2+}$ post-treatment, the capsule was further processed in $2 \% \mathrm{CaCl}_{2} \cdot 2 \mathrm{H}_{2} \mathrm{O}$ solution (w/v) at room temperature for $10 \mathrm{~min}$. Then the capsule was rinsed with excessive water again. One capsule was produced per beaker because the growing alginate capsules tend to stick together. Alginate solution was replaced for each new capsule. All capsules were examined for capsule shell thickness and capsule diameter under a light microscope equipped with a scaled ocular (SZ40, Olympus, Tokyo, Japan). Then, capsule hardness was measured using a hand-made capsule hardness tester (Fig S1, supplementary material) that measures the force it takes to rupture a capsule.

The effect of the capsule volume on the capsule hardness

$\mathrm{Ca}^{2+}$-alginate capsules of different sizes were manufactured by dripping the $\mathrm{Ca}^{2+}$-xanthan core solution of different volumes into the alginate solution. The volume of a single droplet of $\mathrm{Ca}^{2+}$-containing core solution increases with the diameter of the orifice of the dripping device. The orifice of the commercially available disposable syringes (Norm-Ject ${ }^{\circledR}$, Henk-Sass Wolf $\mathrm{GmbH}$, Tuttlingen, Germany) is uniformly $\varnothing 2 \mathrm{~mm}$, irrespective of the syringe size. A syringe with a larger orifice was prepared by cutting off the end of the barrel of a 1-ml syringe whose inner diameter was $4.5 \mathrm{~mm}$. The volume of a single droplet was calculated from the weight of a droplet, as the density of the solution was almost $1\left(d=0.9997 \mathrm{~g} \mathrm{ml}^{-1}\right)$. The volume of a single droplet of $\mathrm{Ca}^{2+}$-xanthan core solution from syringes with an orifice of $\varnothing 2$ and $\varnothing 4.5 \mathrm{~mm}$ was approximately 50 and $100 \mu \mathrm{l}(52.9 \pm 0.4$ and $92.4 \pm 1.0$, respectively; mean $\pm \mathrm{SE}, n=10$ ). Capsules of even larger volumes were formed by dripping multiple droplets of the core solution on top of each other, which resulted in capsules with an oval shape. Thus, we produced $\mathrm{Ca}^{2+}$ alginate capsules from a single droplet of the core 
solution from a Ø2.0-mm syringe (ca. $50 \mu \mathrm{l}$ ) and one, two and three droplets from a $\varnothing 4.5-\mathrm{mm}$ syringe (ca. 100, 200 and $300 \mu \mathrm{l}$, respectively). The formation of capsules was carried out on ice and post-treated in a $2 \% \mathrm{CaCl}_{2} \cdot 2 \mathrm{H}_{2} \mathrm{O}$ solution at room temperature. Then, the different size capsules were all examined for capsule shell thickness, capsule diameter and capsule shell hardness as described above.

EPN escape from alginate capsules

About $2.25 \times 10^{3}$ EPNs were harvested on a filter paper using a Buchner funnel $(\varnothing 60 \mathrm{~mm})$ and suspended in $7.5 \mathrm{ml}$ of $\mathrm{Ca}^{2+}$-xanthan core solution in a 15-ml Falcon tube by repeatedly inverting the tube. This was done gently in order not to form bubbles in the solution. A droplet of the $\mathrm{Ca}^{2+}$-xanthan solution containing EPNs (ca. $50 \mu \mathrm{l}, 150$ EPNs) was dripped from a 1-ml disposable syringe into about $20 \mathrm{ml}$ of alginate solution and the EPN capsules were formed as described above. Ninety-six capsules for each capsule type were produced and individually placed in a 5-ml glass vial. Vials were stored in 500-ml plastic containers with the lid closed. The vials were placed in the dark in an incubator at $24{ }^{\circ} \mathrm{C}$. In this way, the humidity of alginate capsules was maintained and EPN mortality in and out of alginate capsules was barely observed. EPNs that escaped from each capsule were retrieved from each vial with $500 \mu \mathrm{l}$ of water and were counted after seven days.

\section{Statistics}

Capsule size, capsule shell thickness, capsule hardness and EPN escape from different types of capsules were analyzed using SAS (SAS 9.3, SAS Inc.). All the data were tested for normality and equal variances, and means were tested for significant differences using one-way ANOVA test or Kruskal-Wallis test, accordingly. Multiple comparisons of data were conducted using post-hoc Tukey's test $(p<0.05)$.

\section{Results}

The effect of the reaction temperature on the physical properties of alginate capsules

First we explored the effect of the reaction temperature on the physical properties of alginate capsules over time (Fig. 1). As the temperature of alginate solution on ice was about $4{ }^{\circ} \mathrm{C}$ and room temperature was maintained at about $24{ }^{\circ} \mathrm{C}$, we use $4{ }^{\circ} \mathrm{C}$ and $24{ }^{\circ} \mathrm{C}$ instead of 'on ice' and 'room temperature', respectively, throughout this study for convenience sake. Capsule shell thickness and capsule diameter increased gradually over time at both 4 and $24{ }^{\circ} \mathrm{C}$ (Fig. 1a, b; Fig. 1a, capsule shell thickness; $24{ }^{\circ} \mathrm{C}, \chi^{2}=30.4276$, $d f=6, \quad p<0.0001, \quad n=5 ; \quad 4{ }^{\circ} \mathrm{C}, \quad \chi^{2}=30.1107$, $d f=6, p<0.0001, n=5$; Fig. 1b, capsule diameter; $24{ }^{\circ} \mathrm{C}, \chi^{2}=31.1747, d f=6, p<0.0001, n=5$; $\left.4{ }^{\circ} \mathrm{C}, \chi^{2}=27.0683, d f=6, p=0.0001, n=5\right)$, but more slowly at $4{ }^{\circ} \mathrm{C}$. These results suggest that alginate molecules accumulate on the capsule shell more slowly via the ionic interaction with $\mathrm{Ca}^{2+}$ ions at the lower reaction temperature. The capsule hardness did not increase over time but tended to decrease after 20-30 min of reaction although the difference of capsule hardness was not statistically significant (Fig. 1c; capsule hardness; $24{ }^{\circ} \mathrm{C}, \chi^{2}=6.7495, d f=$ $6, p=0.3446, n=5 ; 4{ }^{\circ} \mathrm{C}, \chi^{2}=6.214, d f=6$, $p=0.3996, n=5$ ). However, when data were pooled for the different time points, a significant difference in the capsule hardness at different reaction temperatures was revealed: the capsules produced at $4{ }^{\circ} \mathrm{C}$ were significantly harder to burst than those produced at $24{ }^{\circ} \mathrm{C}$ (Fig. 1d, capsule hardness, $263.6 \pm 20.6 \mathrm{~g}$ at $4{ }^{\circ} \mathrm{C}$ and $143.1 \pm 14.0 \mathrm{~g}$ at $24^{\circ} \mathrm{C}, \chi^{2}=24.4033$, $d f=1, p<0.0001, n=35$ ). These results indicate that the reaction temperature is more critical for capsule hardness than the reaction time. Based on these findings, 20 min was selected as the reaction time for further tests.

The effect of the post-treatment of alginate capsules with excessive $\mathrm{Ca}^{2+}$ ions on the physical properties of alginate capsules

Four types of capsules were produced at 4 or $24{ }^{\circ} \mathrm{C}$ and with or without $\mathrm{Ca}^{2+}$ post-treatment, and their physical properties were determined (Fig. 2). Capsule shell thickness and capsule diameter were highest in the capsules produced at $24{ }^{\circ} \mathrm{C}$ without $\mathrm{Ca}^{2+}$ posttreatment and lowest at $4{ }^{\circ} \mathrm{C}$ with $\mathrm{Ca}^{2+}$ post-treatment (Fig. 2a, capsule shell thickness, $F_{3,36}=71.71$, $p<0.0001, n=10$; Fig. 2b, capsule diameter, $\chi^{2}=30.8913, d f=3, p<0.0001, n=10$ ). In contrast, capsule hardness showed the opposite pattern with the hardest capsules formed at $4{ }^{\circ} \mathrm{C}$ with the $\mathrm{Ca}^{2+}$ 
Fig. 1 Effect of the reaction temperature on a capsule shell thickness, b capsule size and c capsule strength over time $(n=5)$. d Data in (c) pooled by the reaction temperature $(n=35)$. Data are presented as mean \pm SE. Bars with at least one common letter on top represent means which are not significantly different $(p<0.05)$. In $\mathbf{a}$ and $\mathbf{b}$, capital letters are for $24{ }^{\circ} \mathrm{C}$ and lower-case letters for $4{ }^{\circ} \mathrm{C}$. In c, n.s. designates 'means not significantly different'
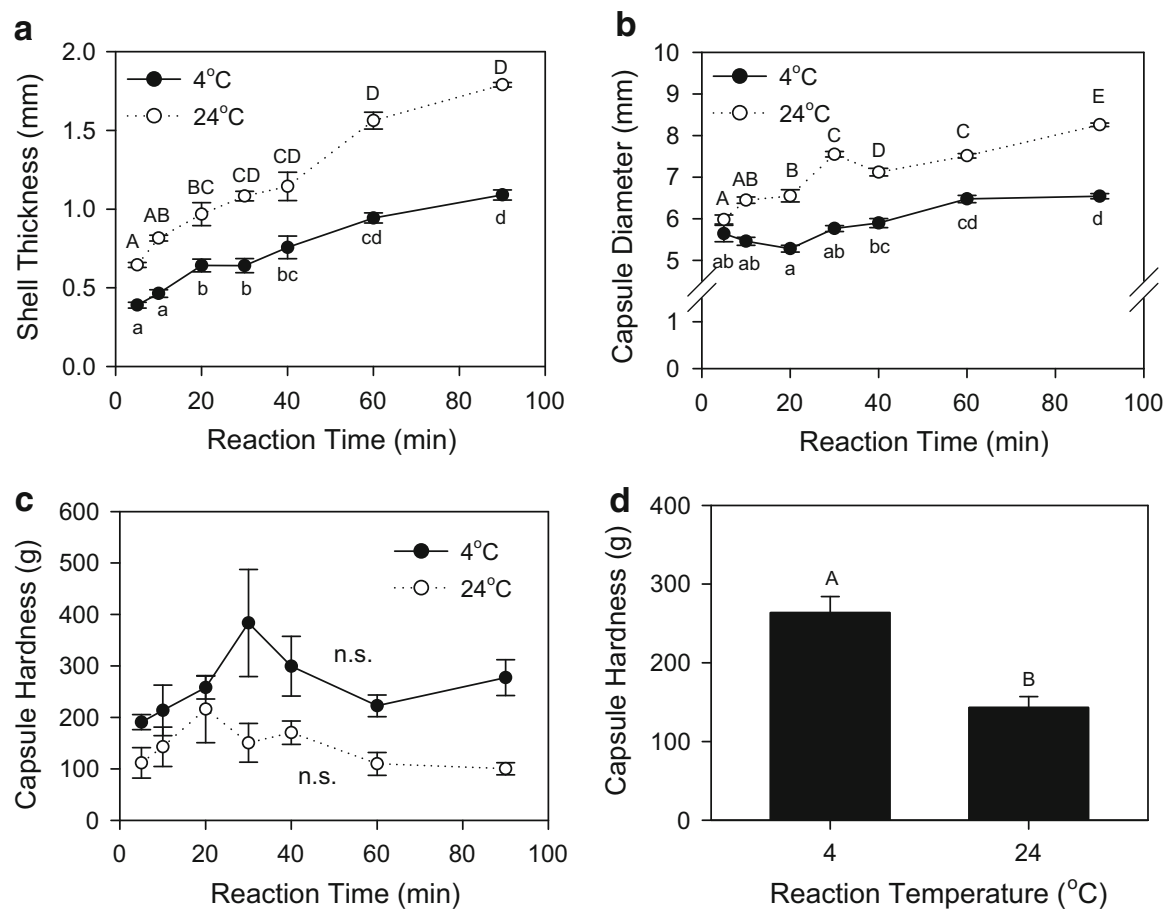

post-treatment (Fig. 2c, capsule hardness, $\left.\chi^{2}=20.1565, d f=3, p=0.0002, n=10\right)$. The effect of the $\mathrm{Ca}^{2+}$ post-treatment on the capsule hardness was evident irrespective of the reaction temperature. The enhanced robustness in the capsule shell structure probably came from tight crosslinking within and among alginate molecules by excessive $\mathrm{Ca}^{2+}$ ions, which further resulted in reduced capsule shell thickness (Fig. 2a). The low reaction temperature appears also important in the formation of harder capsules, as the post-treatment of excessive $\mathrm{Ca}^{2+}$ ions did not strengthen the capsules produced at $24{ }^{\circ} \mathrm{C}$ as much as those produced at $4{ }^{\circ} \mathrm{C}$ (Fig. 2c).

The effect of the capsule volume on the capsule hardness

We also investigated how capsule properties change as the capsule size increases. $\mathrm{Ca}^{2+}$-alginate capsules of different sizes were manufactured as described in the Materials and Methods section and examined for capsule shell thickness, capsule size and capsule shell hardness (Fig. 3). Capsule shell thickness barely changed with capsule size (Fig. 3a, $y=0.59+3.46 \times 10^{-4} x$, $R^{2}=0.949, p=0.0256, n=10$ ), whereas bigger droplets of $\mathrm{Ca}^{2+}$-xanthan core solution produced bigger capsules (Fig. 3b, capsule diameter, simple regression, $y=4.44+0.016 x, R^{2}=0.964, p=0.0183, n=10$ ). Capsule hardness increased almost linearly with the volume of the $\mathrm{Ca}^{2+}$-xanthan core solution per capsule (Fig. 3c, capsule hardness, simple regression, $y=$ $160.84+1.78 x, R^{2}=0.9970, p=0.0015 ; n=10$ ).

EPN escape from alginate capsules with improved physical properties

We investigated whether the enhanced capsule hardness resulted in improved EPN retainment in the capsule core. EPNs encapsulated in the alginate capsules manufactured at different reaction temperatures with or without $\mathrm{Ca}^{2+}$ post-treatment were alive and actively moving in the liquid capsule core (Fig. 4). Ninety six EPN capsules were produced for each type of capsules, individually placed in 5-ml glass vials, and stored in 500-ml plastic containers with the lid closed in the dark in the incubator at $24{ }^{\circ} \mathrm{C}$. As most escapes of EPNs from alginate capsules occurred 4-5 days after encapsulation in the preliminary experiments, EPN escape was determined seven days after encapsulation (Fig. 5). Although capsule hardness was highest when alginate capsules were produced at $4{ }^{\circ} \mathrm{C}$ with the $\mathrm{Ca}^{2+}$ post-treatment (Fig. 2), the EPN 


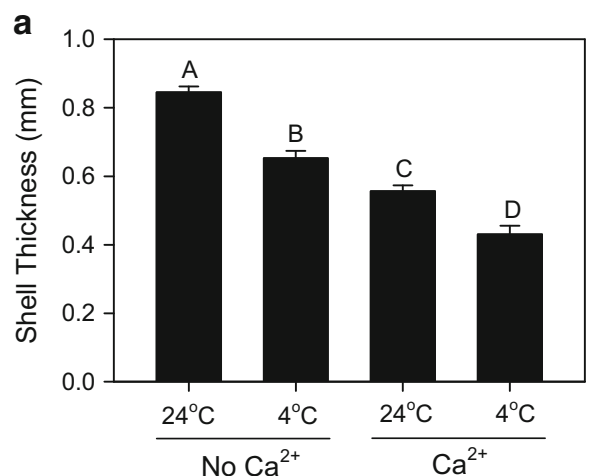

b
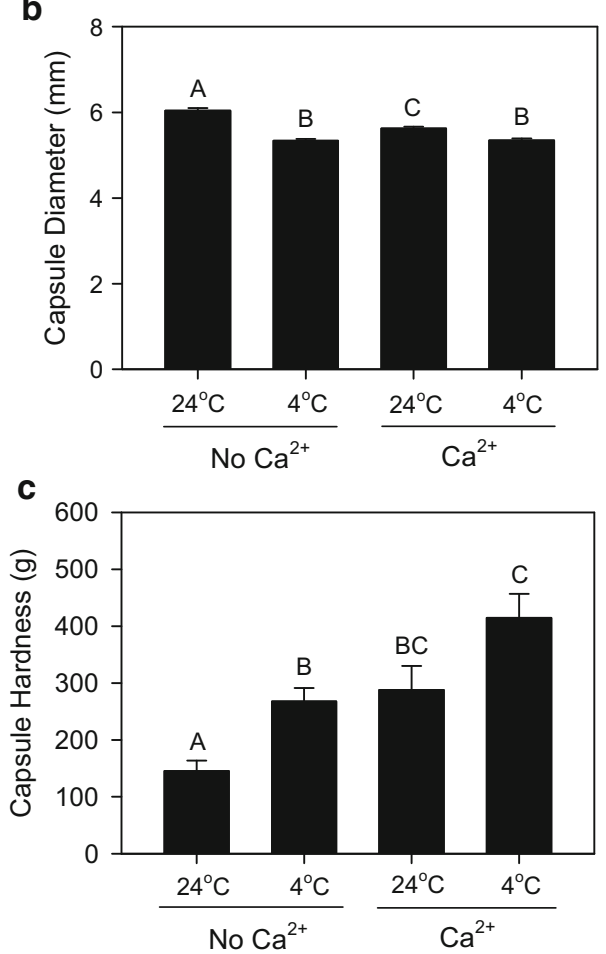

Fig. 2 Effect of the post-treatment of alginate capsules with excessive $\mathrm{Ca}^{2+}$ ions on a capsule shell thickness, $\mathbf{b}$ capsule size and c capsule strength $(n=10) . \mathrm{Ca}^{2+}$ in the graph indicates 'with $\mathrm{Ca}^{2+}$ post-treatment' and $\mathrm{No} \mathrm{Ca}^{2+}$ 'without $\mathrm{Ca}^{2+}$ posttreatment'. Data are presented as mean + SE. Bars with at least one common letter on top represent means which are not significantly different $(p<0.05)$

retainment was highest in the capsules formed at $4{ }^{\circ} \mathrm{C}$ without the $\mathrm{Ca}^{2+}$ post-treatment (Fig. 5, escaped nematode count, $\chi^{2}=29.8346, d f=3, p<0.0001$, $n=96$ ). When the data were pooled for the reaction temperature or for $\mathrm{Ca}^{2+}$ post-treatment, the lower reaction temperature was found to significantly enhance EPN retainment (escaped nematode count, $71.0 \pm 4.4$ at $24{ }^{\circ} \mathrm{C}$ and $45.5 \pm 3.9$ at $4{ }^{\circ} \mathrm{C}, \chi^{2}=18.4714, d f=1$,
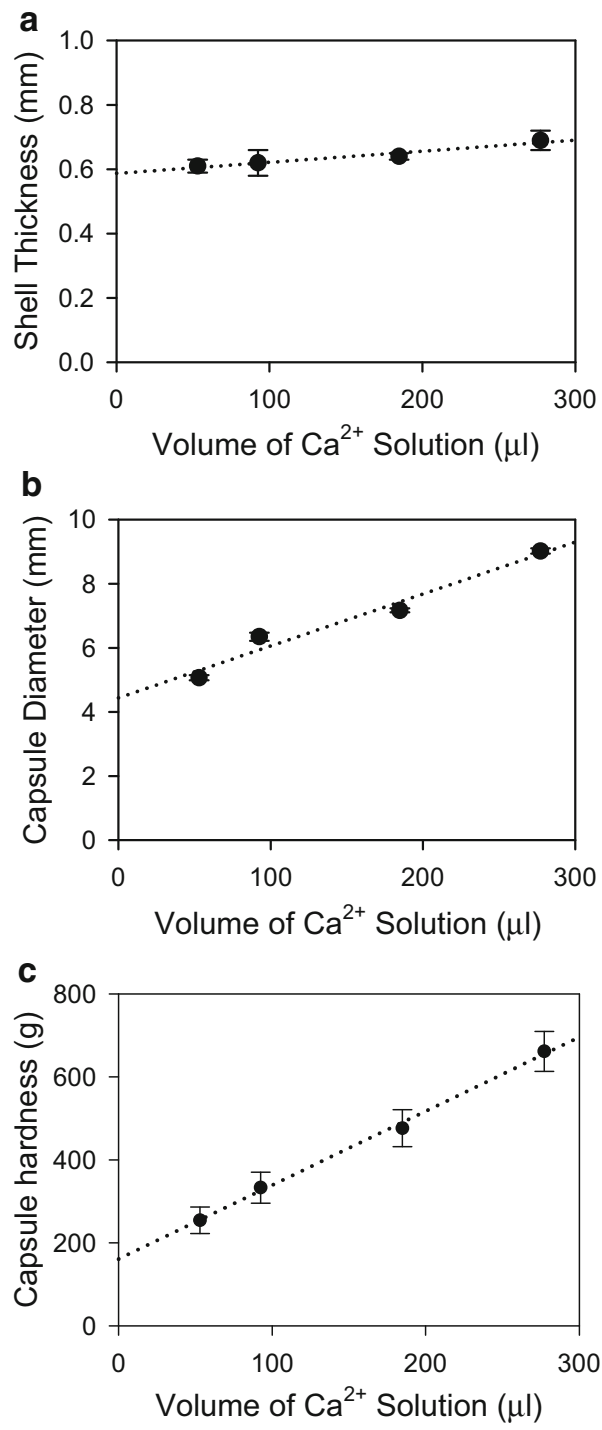

Fig. 3 Effect of the volume of $\mathrm{Ca}^{2+}$-containing core solution on a capsule shell thickness, $\mathbf{b}$ capsule size and c capsule strength $(n=10)$. Data are presented as mean \pm SE. The dotted lines indicate the regression lines between two factors

$p<0.0001, n=192)$, but the $\mathrm{Ca}^{2+}$ post-treatment facilitated EPN escape from alginate capsules (escaped nematode count, $47.1 \pm 3.9$ without $\mathrm{Ca}^{2+}$ post-treatment and $69.5 \pm 4.4$ with $\mathrm{Ca}^{2+}$ post-treatment, $\chi^{2}=$ 11.1789, $d f=1, p=0.0008, n=192)$.

\section{Discussion}

We studied alginate capsule formation at different temperatures over time and tested the conditions to 


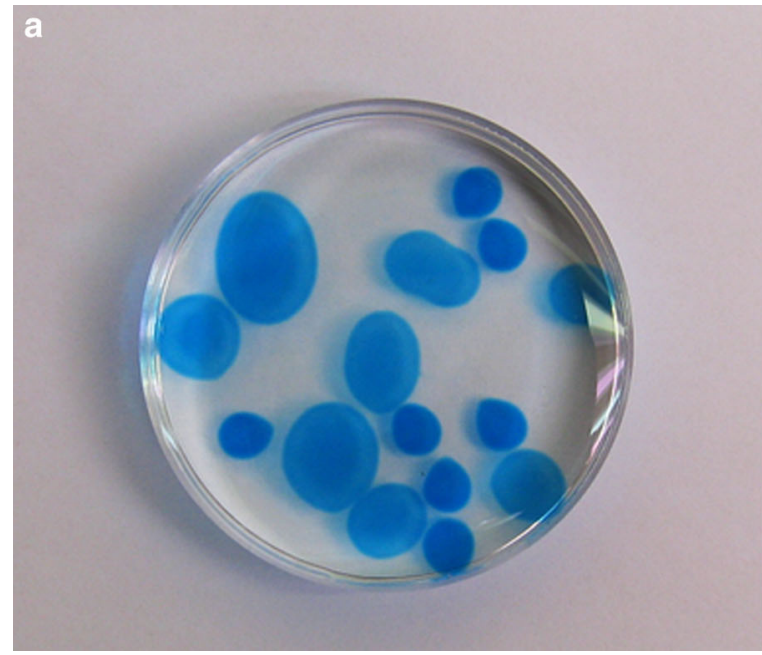

Fig. 4 Photographs of alginate capsules. a Alginate capsules of different sizes in a Ø60-mm petri dish. The volume of the largest capsule was about $500 \mu$ l. The capsule shell was stained in $0.1 \%$ blue dye after production to more clearly visualize the

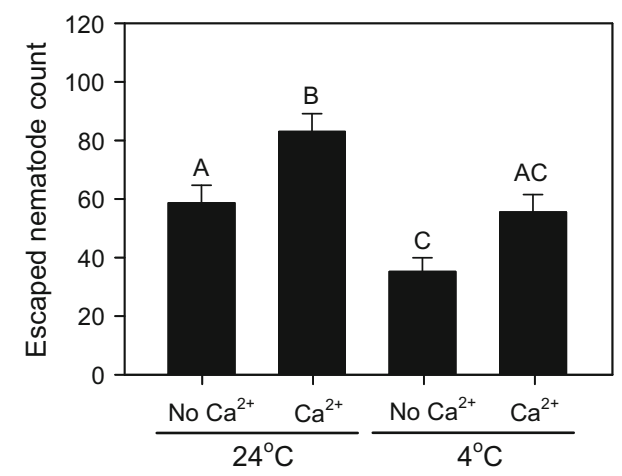

Fig. 5 Effect of the reaction temperature and the $\mathrm{Ca}^{2+}$ posttreatment on the EPN escape from alginate capsules. EPN capsules were produced at 4 or $24{ }^{\circ} \mathrm{C}$ with or without $\mathrm{Ca}^{2+}$ posttreatment, and the number of EPNs that escaped from alginate capsules was counted sevsn days after encapsulation $(n=96)$. $\mathrm{Ca}^{2+}$ and $\mathrm{No} \mathrm{Ca}^{2+}$ in the graph indicate 'with $\mathrm{Ca}^{2+}$ posttreatment' and 'without $\mathrm{Ca}^{2+}$ post-treatment', respectively. Data are presented as mean + SE. Bars with at least one common letter on top represent means which are not significantly different $(p<0.05)$

produce capsules with greater shell hardness and better EPN retainment by modulating the reaction temperature during capsule formation and employing post-treatment of alginate capsules with excessive $\mathrm{Ca}^{2+}$ ions. We hypothesized that a more finely and evenly formed capsule shell structure will lead to increased capsule hardness, which will result in

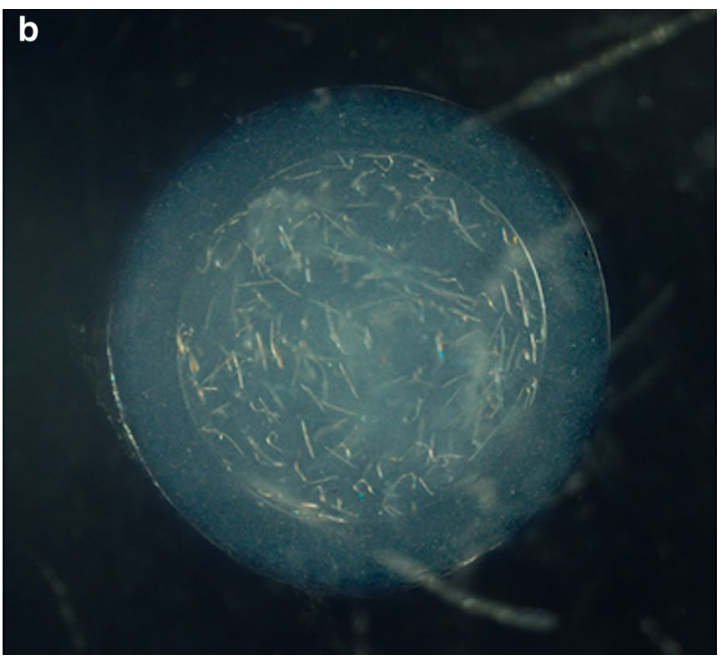

capsule shell. b Heterorhabditis bacteriophora nematodes encapsulated in the alginate capsule shell produced at $4{ }^{\circ} \mathrm{C}$ with $\mathrm{Ca}^{2+}$ post-treatment

enhanced EPN retainment in the alginate capsules. To test this possibility of improving the physical properties of the $\mathrm{Ca}^{2+}$-alginate framework in the capsule shell, we varied the reaction temperature during alginate gelation and studied the effects of $\mathrm{Ca}^{2+}$ post-treatment. Both the lower reaction temperature and the $\mathrm{Ca}^{2+}$ post-treatment significantly strengthened the capsule shell. EPN retainment, however, was only improved as a result of the lower reaction temperature, whereas the post-treatment of alginate capsules with excessive $\mathrm{Ca}^{2+}$ ions made alginate capsules more permeable to EPNs. We also considered the possibility that $\mathrm{CaCl}_{2} \cdot 2 \mathrm{H}_{2} \mathrm{O}$ is toxic to the EPNs, but this is not evident from the presented results and further preliminary experiments. Still, if a small amount of $\mathrm{CaCl}_{2} \cdot 2 \mathrm{H}_{2} \mathrm{O}$ ended up in the capsule core after $\mathrm{Ca}^{2+}$ post-treatment, it might have affected EPN behavior and possibly their escape rate.

The results show that both the low reaction temperature and the $\mathrm{Ca}^{2+}$ post-treatment of alginate capsules significantly enhance the physical structure of alginate capsules. The capsulation process in the present study is an improved version of that of Hiltpold et al. (2012). In this system, the amount of $\mathrm{Ca}^{2+}$ ions in the capsule core solution is limited, whereas the supply of alginate molecules from the alginate solution surrounding the growing capsule shell is nearly unlimited. Xanthan incorporated in the 
$\mathrm{Ca}^{2+}$-containing capsule core solution increases the viscosity of the core solution and prevents the capsule core from dissipation during capsule shell formation. During capsule formation, alginate molecules are complexed with $\mathrm{Ca}^{2+}$ ions at the interface between the core and the surrounding alginate solution, whereby the shell grows outward (Fig. 1a, b).

The low reaction temperature significantly enhanced the hardness of alginate capsules (Figs. 1d, 2c), which is probably due to slower molecular movement of alginate polymers and their interaction with $\mathrm{Ca}^{2+}$ ions, leading to a finer alignment of alginate polymers on the boundary between alginate solution and the growing capsule shell. However, with the limited amount of $\mathrm{Ca}^{2+}$ in the capsule core itself, a continuous supply of alginate molecules from the alginate solution may have weakened the capsule shell structure after 20-30 min of the reaction time (Fig. 1c). The data imply that $\mathrm{Ca}^{2+}$ ions participating in the $\mathrm{Ca}^{2+}$-alginate gel structure were recruited for newly-arrived alginate building blocks, resulting in the decrease of the ratio of $\mathrm{Ca}^{2+}$ ions to alginate molecules across the capsule shell, which must have reduced capsule hardness.

Post-treatment of alginate capsules with $\mathrm{CaCl}_{2}$ solution enhanced the capsule hardness remarkably (Fig. 2c). It is likely that excessive $\mathrm{Ca}^{2+}$ ions formed many ionic bridges within and among alginate polymers, which normally are only loosely crosslinked under conditions with a limited amount of $\mathrm{Ca}^{2+}$ ions in the capsule core (King 1982). Newly formed $\mathrm{Ca}^{2+}$ alginate ionic bonds will certainly have pulled alginate polymers closer, resulting in increased capsule hardness (Fig. 2c) and reduced shell thickness (Fig. 2a). However, the $\mathrm{Ca}^{2+}$ post-treatment seems to exert an adverse effect on the EPN retainment in alginate capsules (Fig. 5). Our best interpretation of these unexpected results is that increased crosslinking of alginate polymers with $\mathrm{Ca}^{2+}$ ions might reduce the resilience of capsule shell, rendering the perforation(s) made by EPNs less recoverable.

The capsule size could be important for practical reasons such as easy handling, a higher dose of EPNs per capsule, or a more efficient mass-production of EPN capsules. As described above, we manufactured considerably larger capsules than previously used using a projector with a larger orifice or dropping multiple droplets of the capsule core solution. However, the effect of increased size of $\mathrm{Ca}^{2+}$-alginate capsules on capsule properties remained unclear. It turned out that, as volume of $\mathrm{Ca}^{2+}$-containing core solution increased, capsules got bigger in size and harder to burst, whereas capsule shell barely thickened (Fig. 3). Little difference in capsule shell thickness of capsules means shell thickness is the function of reaction time, neither the volume of nor the total $\mathrm{Ca}^{2+}$ ions in the $\mathrm{Ca}^{2+}$-containing core solution (Fig. 3a). Correlation between volume of $\mathrm{Ca}^{2+}$-containing core solution and capsule size is as expected (Fig. 3b). The linear increase of the capsule hardness with volume of $\mathrm{Ca}^{2+}$-containing core solution is practically interesting outcome of this study. These results provide a basis for the production of alginate capsules as large as seeds of crop plants such as maize, which may be practically favored for easy handling and "planting" of capsules, and can hold a higher EPN dose per capsule.

There are a few previous reports on alginate-based EPN capsules. The first capsules were manufactured by dripping alginate solution containing EPNs into $\mathrm{CaCl}_{2}$ solution (Kaya and Nelsen 1985). This approach is based on a limited amount of alginate molecules in the core solution complex with a nearly unlimited supply of $\mathrm{Ca}^{2+}$ ions from the surrounding $\mathrm{CaCl}_{2}$ solution. Contrary to our approach, the capsule shell grows inward, leaving, if any, only a small portion of the capsule core in a liquid state. The resultant capsules are smaller than those presented here (approximately $1.5 \mathrm{~mm} v \mathrm{~s} .4-5 \mathrm{~mm}$ in diameter, respectively). For this reason, these types of capsules are often called as beads (Vemmer and Patel 2013). They have a high ratio of $\mathrm{Ca}^{2+}$ ions over alginate molecules within $\mathrm{Ca}^{2+}$-alginate framework, which explains why EPNs hardly escape from $\mathrm{Ca}^{2+}$-alginate beads without breakage of the gel matrix by e.g. insect feeding or germinating tomato seeds (Kaya and Nelsen 1985; Kaya et al. 1987).

The most recent report of alginate-based EPN capsules introduced a few important modifications (Hiltpold et al. 2012). Instead of $\mathrm{CaCl}_{2}$, Gluco ${ }^{\circledR}$ (a mixture of calcium salts of lactic and gluconic acids; FDA-approved food additive) was used as the calcium source. Xanthan, a polysaccharide that is also nontoxic to EPNs, incorporated into the $\mathrm{Ca}^{2+}$-containing core solution allowed production of alginate capsules as large as $1 \mathrm{ml}$ and probably larger. Hiltpold et al. (2012) tested the capsules in maize fields by burying them directly in the soil. EPNs were found to be readily liberated into the rhizosphere and effective in 
controlling an underground insect pest of maize, the Western corn rootworm (D. v. virgifera). However, as mentioned earlier, most of EPNs escaped too fast from the capsules, a problem that was largely resolved in the current study.

The ultimate goal of this research is to develop commercializable EPN capsules to control soildwelling insect pests in the field. The ideal EPN capsules will (1) retain EPNs inside the capsule until needed, (2) keep EPNs healthy and infectious for a long period at room temperature, (3) be co-planted into the soil with the seeds of crop plants, (4) release EPNs into the rhizosphere before the soil insect pests appear in the field, and (5) attract the soil insect pests towards EPN capsules by incorporating insect attractants and/or feeding stimulants in the capsule. As the next step in our ongoing research, further improvements of EPN capsules are under development that will allow for prolonged shelf life and controlled release of EPNs.

Acknowledgments We thank Dr. Thomas Degen for his illustration included in this paper. This work was supported by a grant from the Swiss National Science Foundation (Grant No. 51NF40-144621).

\section{References}

Gaugler R, Lewis E, Stuart RJ (1997) Ecology in the service of biological control: the case of entomopathogenic nematodes. Oecologia 109:483-489

Georgis R, Kaya HK (1998) Formulation of entomopathogenic nematodes. In: Burges HD (ed) Formulation of microbial biopesticides. Kluwer Academic Publishers, Dordrecht, The Netherlands, pp 289-308

Georgis R, Koppenhöfer AM, Lacey LA, Bélair G, Duncan LW, Grewal PS, Samish M, Tan L, Torr P, van Tol RWHM (2006) Successes and failures in the use of parasitic nematodes for pest control. Biol Control 38:103-123

Hiltpold I, Hibbard BE, Wade French B, Turlings TCJ (2012) Capsules containing entomopathogenic nematodes as a Trojan horse approach to control the Western corn rootworm. Plant Soil 358:11-25

Hoffman AS (2012) Hydrogels for biomedical applications. Adv Drug Deliv Rev 64:18-23

John RP, Tyagi RD, Brar SK, Surampalli RY, Prévost D (2011) Bio-encapsulation of microbial cells for targeted agricultural delivery. Crit Rev Biotechnol 31:211-226
Kaya HK, Gaugler R (1993) Entomopathogenic nematodes. Annu Rev Entomol 38:181-206

Kaya HK, Nelsen CE (1985) Encapsulation of steinernematid and heterorhabditid nematodes with calcium alginate: a new approach for insect control and other applications. Environ Entomol 14:572-574

Kaya HK, Stock SP (1997) Techniques in insect nematology. In: Lacey L (ed) Manual of techniques in insect pathology. Academic Press, San Diego, USA, pp 281-324

Kaya HK, Mannion CM, Burlando TM, Nelsen CE (1987) Escape of Steinernema feltiae from alginate capsules containing tomato seeds. J Nematol 19:287-291

King AH (1982) Brown seaweed extracts (alginates). In: Glicksman M (ed) Food hydrocolloids. CRC Press, Boca Raton, USA, pp 115-188

Koppenhöfer AM (2007) Nematodes. In: Lacey LA, Kaya HK (eds) Field manual of techniques in invertebrate pathology, 2nd edn. Springer, Berlin, Germany, pp 249-264

Lewis EE, Campbell J, Griffin C, Kaya H, Peters A (2006) Behavioral ecology of entomopathogenic nematodes. Biol Control 38:66-79

Peters A (1996) The natural host range of Steinernema and Heterorhabditis spp. and their impact on insect populations. Biocontrol Sci Technol 6:389-402

Shapiro-Ilan DI, Jackson M, Reilly CC, Hotchkissa MW (2004) Effects of combining an entomopathogenic fungi or bacterium with entomopathogenic nematodes on mortality of Curculio caryae (Coleoptera: Curculionidae). Biol Control 30:119-126

Shapiro-Ilan DI, Gouge DH, Piggott SJ, Fife JP (2006) Application technology and environmental considerations for use of entomopathogenic nematodes in biological control. Biol Control 38:124-133

Shapiro-Ilan DI, Han R, Dolinksi C (2012) Entomopathogenic nematode production and application technology. J Nematol 44:206-217

Tønnesen HH, Karlsen J (2002) Alginate in drug delivery systems. Drug Dev Ind Pharm 28:621-630

Vemmer M, Patel AV (2013) Review of encapsulation methods suitable for microbial biological control agents. Biol Control 67: 380-389

Jinwon Kim is the main investigator on a project to develop capsules for the release of entomopathogenic nematodes against the western corn rootworm, an invasive pest in Europe.

Geoffrey Jaffuel is a $\mathrm{PhD}$ student. His research aims to enhance the shelf-life and performance of entomopathogenic nematodes as biological control agents against root pests.

Ted C. J. Turlings is head of the FARCE research group, whose main focus is the chemical ecology of plant-insect interactions in agro-ecosystems. 